\title{
IMPROVING THE ACCURACY OF SENSORS IN AIR-CONDITIONING SYSTEMS
}

\author{
Huiling Tan and Arthur Dexter
}

Department of Engineering Science

University of Oxford, UK.

\begin{abstract}
Improving the accuracy of the measurements in building automation systems without increasing operational costs is an essential step if the overall comfort and energy efficiency of buildings are to be improved. Data reconciliation and gross error elimination have emerged as key techniques for reducing both random noise and gross errors on the outputs of sensors. This paper focuses on using actuator control signals and simulation based on computational fluid dynamics to achieve the level of redundancy that is necessary for simultaneous data reconciliation and gross error elimination to be applied air-conditioning systems. Copyright $@ 2005$ IFAC
\end{abstract}

Keywords: sensor fusion, measurement errors, bias estimation, flow measurement, temperature measurement.

\section{INTRODUCTION}

Reliable process data are the basis for efficient process monitoring, operation and control. Inaccurate measurements will undermine the performance of optimum control schemes, and consequently result in extra energy consumption. According to the research of Kao and Pierce (1983) an error in a mixed air temperature sensor of $+2.8{ }^{\circ} \mathrm{C}$ can produce a $60 \%$ increase in cooling energy consumption, and a -2.8 ${ }^{\circ} \mathrm{C}$ error produce a heating waste of over $30 \%$.

In many air-conditioning systems, airflow rates and some important air temperatures are not measured, or not measured accurately, usually because of concern about cost or installation problems resulting from space limitations. Previous research has raised doubts about the accuracy of some measurements used by building automation systems. Carling and Isakson (1999) found that the temperature difference between the air in the lower and upper parts of a duct downstream the mixing box can be considerable and that standard single point temperature sensors are not sufficient when measuring air temperatures downstream of mixing boxes. According to a research by Avery (2002), even an average temperature sensor is not accurate enough for satisfactory control because of installation limitations in real air-conditioning systems. Simulation results have showed that the bias associated with a 6-point average sensor can be as large as $4{ }^{\circ} \mathrm{C}$ when it is installed downstream of the mixing box (Lee and
Dexter, 2002). Similar problem occurs in the measurement of airflow rates in air-conditioning systems. Measurements of the airflows are usually unsatisfactorily because of turbulence and stratification in the airflow. Ventilation airflow measurement has been an active research topic for many years, (Felker, 2002; Drees, et al., 1992; Solberg, et al., 1990), but there is still no accurate measurement scheme, which is cheap and easy to install and maintain.

Measurement errors have also been identified as a major obstacle to the successful application of performance monitoring and fault detection tools in HVAC systems (Annex 34, 2001). All fault diagnosis schemes rely on the availability of accurate sensors as erroneous measurements will hinder the fault diagnosis process and can easily lead to false alarms and incorrect diagnoses (Lee and Dexter, 2002). Improving the accuracy of measurements in building automation systems without increasing operation cost is an essential step if the overall comfort and energy efficiency of buildings are to be improved.

Measurement errors have two components: random errors and gross or bias errors. Random errors are inherent to the measurement process. Gross errors are deterministic in nature and are caused by incorrect calibration or installation, drift or deterioration of the instrumentation. In ducted HVAC systems, air stratification can result in airflow rate and 
temperature sensors having significant bias errors (Robinson, 1999; Mainkar, et al., 2004).

Many methods have been proposed for reducing random errors in measurements. For example, data reconciliation can be used to reduce random measurement errors through the use of temporal or spatial redundancies, such as mass and energy balance equations (Crowe, 1996). However, the presence of gross errors invalidates the statistical basis of many schemes and they must be identified and eliminated before the random errors can be reduced (Singh, et al., 2001). Simultaneous data reconciliation and gross error elimination has emerged as a key part of on-line optimisation and have been the subject of much research effort (Ozyurt and Pike, 2004; Wang, 2004). Several approaches have been suggested to reduce random errors and gross errors simultaneously. One general method is state augmentation, where the bias errors are appended to the state vector to form an augmented system that can be estimated on-line for both the state and the bias values (Musick and Kastella, 2002).

Both gross error elimination and data reconciliation rely on information redundancy. The number of constraints limits the maximum number of gross errors that can be estimated as free parameters. For a system in which the number of biased measurements is more than the number of process equations, the redundancy level of the system must be increased if all measurement biases are to be estimated. Wang and Wang (1999) increased the number of process equations and thus increased the system redundancy level by assuming the measurement biases are constant and collecting process data for different modes of operation. In the mixing box of an airconditioning system, the bias associated with the mixed air measurement varies with operating conditions and therefore depends on, for example, the control signal for the dampers, the temperature difference between the outside air and return air. Consequently, the collection of process data at different operating modes cannot be used to increase the level of redundancy in the system.

Redundancy can also be introduced by replicating measurements or by estimating the bias rather than treating it as a free parameter (Wang, 2004). This paper focuses on using actuator control signals and Computational Fluid Dynamics (CFD) to achieve the level of redundancy that is necessary for simultaneous data reconciliation and gross error elimination to be applied to air-conditioning systems. The use of actuator control signals to estimate the airflow rates is investigated, as is the use of CFD simulation to estimate of the time-varying bias on the output of a mixed air temperature sensor.

\section{ESTIMATION OF AIRFLOW RATES USING ACTUATOR CONTROL SIGNALS}

Since the actuator control signals for the mixing box dampers, supply fan and return fan are available through Building Energy Management Systems (BEMSs), these control signals can provide additional information which can be used for the estimation of the airflows in the air-conditioning system.

The air-circuits of a Variable-air-Volume (VAV) airconditioning system have been simulated to investigate the relationship between the airflow rates and actuator control signals (Tan and Dexter, 2004). The simulation results presented in Figure 1 show that, at a given damper position, the relationship between the extract airflow ( $Q_{\text {ext }}$ ) and the return fan control signal ( $U_{\text {fret }}$ ) is linear over the full operating range and that the relationship between the supply airflow rate $\left(\mathrm{Q}_{\text {sup }}\right)$ and the control signal for the supply fan ( $\mathrm{U}_{\mathrm{f} \text { sup }}$ ) is approximately linear when the supply airflow rate is more than $40 \%$ of its design value. However, the results presented in Figure 2 show that there can be a strongly non-linear relationship between the ventilation inlet airflow rate $\left(Q_{\text {in }}\right)$ and the inlet damper control signals $\left(U_{\text {din }}\right)$.
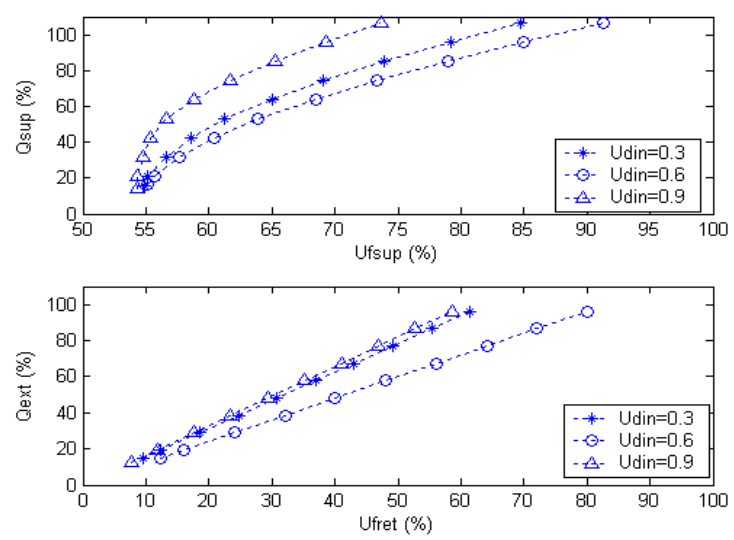

Fig.1 Relationships between Qsup and Ufsup, Qext and Ufret at different values of Udin.

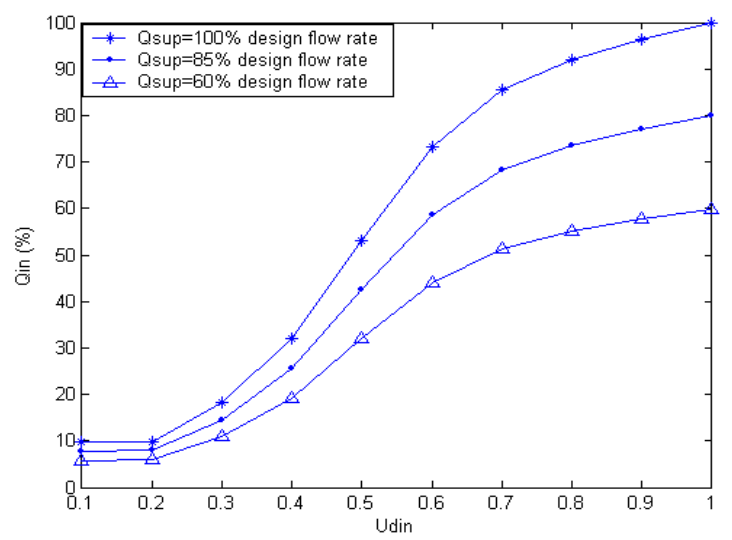

Fig.2 Relationship between Qin and Udin at different values of Qsup. 
The following approach is therefore proposed for estimating the airflow rates:

First, the following linear equations (see equation 2) are used to estimate the supply airflow rate and extract airflow rate from the control signals for supply fan and return fan:

$$
\begin{aligned}
& \mathrm{Q}_{\text {sup }}=\mathrm{k}_{\text {sup }} * \mathrm{U}_{\mathrm{f} \text { sup }}+\mathrm{a}_{\text {sup }} \\
& \mathrm{Q}_{\text {ext }}=\mathrm{k}_{\text {ret }} * \mathrm{U}_{\text {fret }}
\end{aligned}
$$

The parameters $k_{\text {sup }}, k_{\text {ret }}$ and $a_{\text {sup }}$ are determined from calibration data obtained during plant commissioning. The estimators can be implemented in the outstations of the Building Energy Management System (BEMS), which has access to all the measurement data and control signals in the air-conditioning system; or embedded in an intelligent sensor, which can be connected directly to the BEMS network.

Then, a non-linear model of the mixing box (see equation 2) is used to estimate the inlet airflow rate from the estimated values of the supply and extract flow rates.

$$
\begin{aligned}
& \mathrm{Q}_{\text {mix }}=\mathrm{Q}_{\text {ret }}+\mathrm{Q}_{\mathrm{in}} ; \\
& \mathrm{Q}_{\mathrm{ext}}=\mathrm{Q}_{\mathrm{ret}}+\mathrm{Q}_{\mathrm{exh}} ; \\
& \mathrm{P}_{\mathrm{in}}-\mathrm{P}_{\text {mix }}=\mathrm{R}_{\mathrm{in}} * \mathrm{Q}_{\mathrm{in}}{ }^{2} ; \\
& \mathrm{P}_{\mathrm{ext}}-\mathrm{P}_{\mathrm{exh}}=\mathrm{R}_{\mathrm{exh}} * \mathrm{Q}_{\mathrm{exh}}{ }^{2} ; \\
& \mathrm{P}_{\mathrm{ext}}-\mathrm{P}_{\text {mix }}=\mathrm{R}_{\text {ret }} * \mathrm{Q}_{\mathrm{ret}}{ }^{2} ;
\end{aligned}
$$

$\mathrm{R}_{\text {in }}, \mathrm{R}_{\text {exh }}, \mathrm{R}_{\text {ret }}$ are the summation of the resistances of the inlet dampers, exhaust dampers, return dampers and the resistances of the connected duct respectively:

$$
\begin{aligned}
& \mathrm{R}_{\text {in }}=\mathrm{R}_{\mathrm{dmpr}_{\text {_in }}}+\mathrm{R}_{\text {duct_in }} ; \\
& \mathrm{R}_{\text {exh }}=\mathrm{R}_{\mathrm{dmpr}_{\text {_exh }}}+\mathrm{R}_{\text {duct_exh; }} \\
& \mathrm{R}_{\text {ret }}=\mathrm{R}_{\text {dmpr_ret }}+\mathrm{R}_{\text {duct_ret; }}
\end{aligned}
$$

The following equations are widely used to calculate the resistances of dampers from the damper control signal $\alpha$ and design information provided by the damper manufacturer:

$$
\begin{aligned}
& \text { if }(\alpha \geq 0.3333), \mathrm{R}_{\mathrm{dmpr}}=\mathrm{R}_{\text {open }} * \exp (\mathrm{A} *(1-\alpha)) ; \\
& \text { if }(\alpha<0.3333), \mathrm{R}_{\mathrm{dmpr}}=\frac{\mathrm{R}_{\text {open }}}{3.0 *[(1 / 3-\alpha) * \mathrm{~L}+\mathrm{B} * \alpha]^{2}}
\end{aligned}
$$

where $R_{\text {open }}$ is the resistance of the damper when it is fully open; and $L$ is the leakage factor of the damper when it is fully closed. The values of the coefficients $A$ and $B$ depend on the type of dampers used (Legg, 1986).
The resistances of the ducts are calculated from the fully open resistances of the dampers and estimated values of the authorities of the dampers $(\gamma)$ :

$$
\mathrm{R}_{\text {duct }}=\frac{1-\gamma}{\gamma} * \mathrm{R}_{\text {open }}
$$

Using equation (3), (4) and (5), the resistances $\left(R_{\text {in }}, R_{\text {exh }}, R_{\text {ret }}\right.$ ) can be determined from the design parameters, the control signals for the dampers and the estimated values of the damper authorities.

The pressure in the inlet duct ( $P_{i n}$ ) and exhaust duct ( $P_{\text {ext }}$ ) can be assumed to be equal to the atmospheric pressure when they are not measured, as is the case in most air-conditioning systems. The supply airflow rate $\left(\mathrm{Q}_{\text {sup }}=\mathrm{Q}_{\text {mix }}\right)$ and extract airflow rate $\left(\mathrm{Q}_{\text {ext }}\right)$ are either measured or can be estimated using equation (1). Thus, there are only five unknown variables in the five equations describing the operation of the mixing-box (equation (2)): the inlet airflow rate $\left(Q_{\text {in }}\right)$, exhaust airflow rate $\left(Q_{\text {exh }}\right)$, return airflow rate $\left(Q_{\text {ret }}\right)$, pressure after the extract fan $\left(\mathrm{P}_{\mathrm{ext}}\right)$, and pressure after the mixing box $\left(\mathrm{P}_{\mathrm{mix}}\right)$.

The above estimation schemes have been used to estimate the airflow rates in a full-scale airconditioning system at the Iowa Energy Centre (Price et al., 1998). The schemes have been validated by comparing the estimation results and on-site measurements, as shown in Figures 3, 4 and 5.

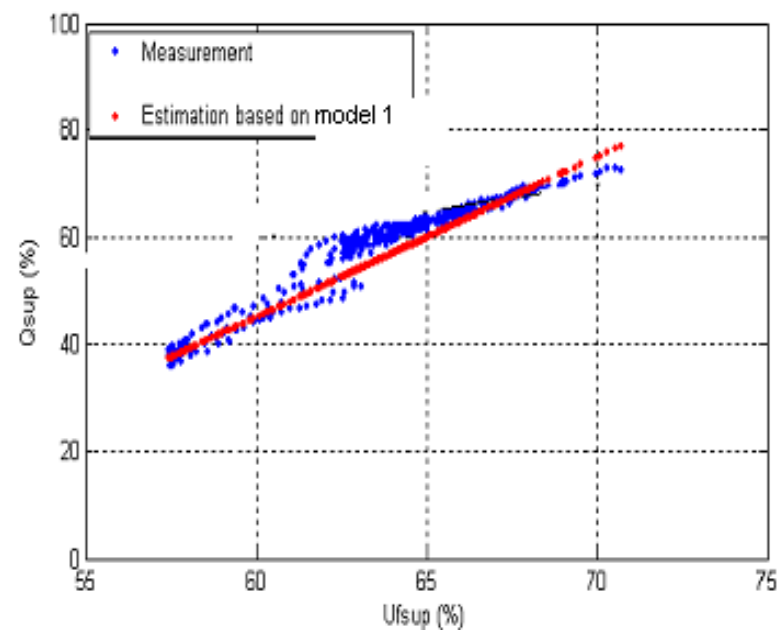

Fig. 3. Estimation of Qsup based on Eqn. 1 compared with measurements.

Figure 3 shows that the errors associated with the estimates of $\mathrm{Q}_{\text {sup }}$ based on equation (1) are less than $10 \%$ of the true value. The errors are mainly caused by transient effects, since the linear approximation is only valid when the system is in steady state. 


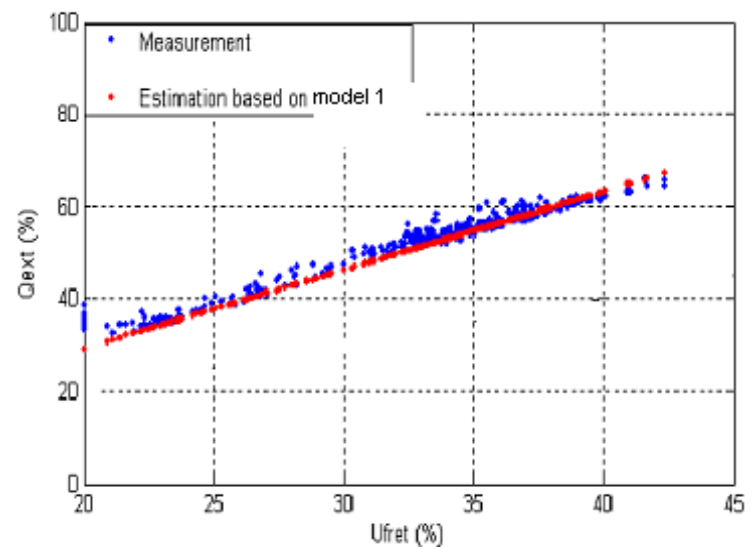

Fig. 4. Estimation of Qext based on Eqn. 1 compared with measurements.

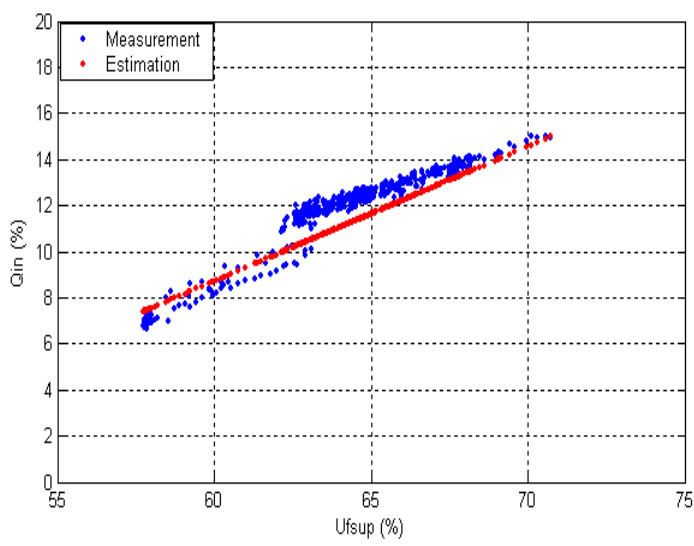

Fig. 5. Estimation of Qin based on Eqn. 1\&2 compared with measurements.

Figures 4 and 5 show that the errors in the estimations of the extract and inlet airflow rates are less than $5 \%$ and $10 \%$ of the true value, respectively. The errors associated with the estimate of $Q_{\text {in }}$ based on equation (2) are caused by a combination of the errors in the measured or estimated values of $\mathrm{Q}_{\text {sup }}$ and $\mathrm{Q}_{\mathrm{ext}}$, and errors in the estimated values of the parameters of the mixing-box model. For example, the uncertainty in the estimated values of the damper authorities can cause an error in $Q_{\text {in }}$ that is up to $5 \%$ of the true value.

\section{USE OF CFD SIMULATION TO ESTIMATE THE BIAS ON THE OUTPUT OF A MIXED AIR TEMPERATURE SENSOR}

CFD has been used previously to investigate the temperature and velocity stratification in mixing boxes under different operating conditions (Kelso et al., 2000; Carling and Zhou, 2001). Here, the bias associated with measurements of the air temperature downstream of a mixing box is estimated using a CFD simulation package.
The boundary settings for the simulation include inlet flow rate, inlet air temperature, return airflow rate and return air temperature. The inlet and return airflow rates at different damper positions are first estimated using the lumped-parameter mixing-box model described earlier and the estimated supply and extract airflow rates [see equations (2) and (3)]. Figure $6 \& 7$ shows the air temperature and velocity contours generated from a 2D CFD simulation when the dampers are all 50\% open.

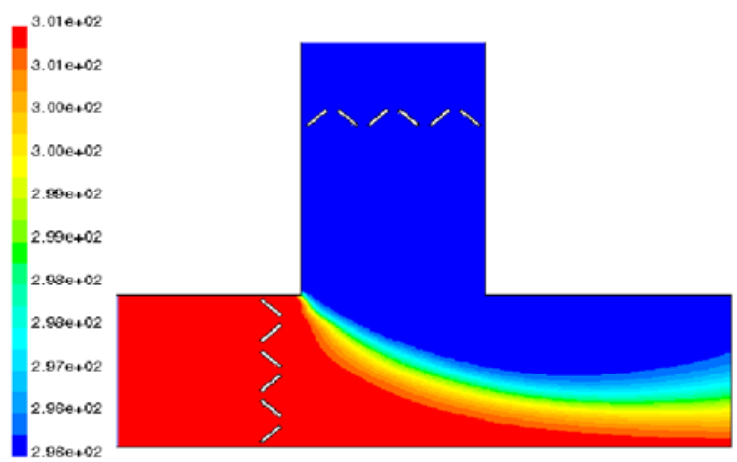

Fig. 6. CFD simulation of the air temperature in the mixing box with dampers $50 \%$ open

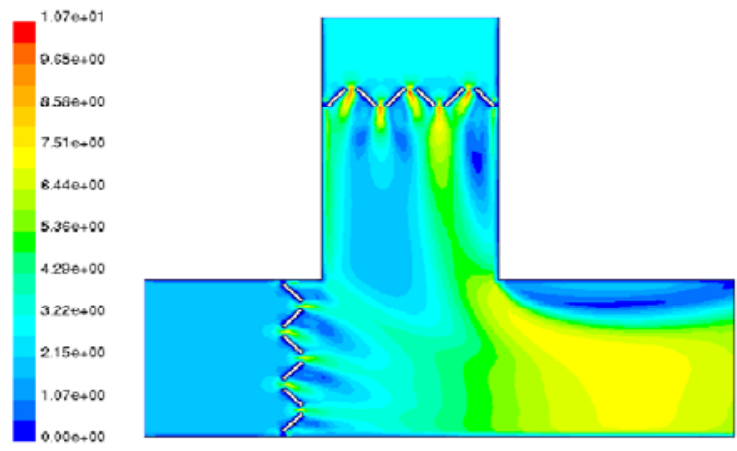

Fig. 7. CFD simulation of the air in the mixing box with dampers $50 \%$ open

The results show that there are significant spatial variations in both the air temperature and velocity, which could result in biased measurements of the average mixed-air temperature if a conventional sensor is used.

The bias $\mathrm{B}$ associated with the measurement is the difference between the temperature indicated by the sensor and the true average temperature. Hence:

$$
\mathrm{B}=\mathrm{T}_{\text {meas }}-\overline{\mathrm{T}}_{\text {true }} .
$$

The true average temperature is given by:

$$
\bar{T}_{\text {true }}=\frac{\int_{L} V T d l}{\int_{L} V d l}
$$


where $\mathrm{T}$ is the local temperatures, $\mathrm{V}$ is the local velocity and $l$ is the vertical distance (Lee and Dexter, 2004). It is assumed that a commercial averaging sensor has its sensing elements equally distributed at a finite number of vertical positions and that the output from the sensor is the algebraic average of the measured temperatures. Hence:

$$
T_{\text {meas }}=\sum_{i} T_{i} / n
$$

where $n$ is the number of sensing elements and $T_{i}$ is the temperature measured at the ith element.

Figure 8 shows the estimated measurement bias, expressed as a percentage of the temperature difference between inlet air and return air, for different damper positions and given, constant values of the simulated outdoor air temperature, return air temperature and supply airflow rate.

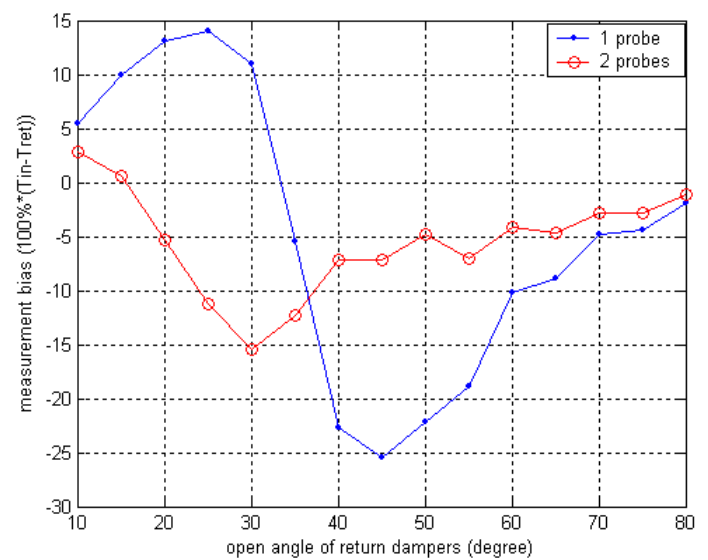

Fig. 8 Biases associated with the measurements from temperature sensors with one and two sensing elements

The maximum bias can be up to $25 \%$ of the temperature difference when a single-point temperature sensor is used, and up to $15 \%$ when a two-point averaging sensor is used.

Parametric studies, undertaken using the CFD simulation, show that for given geometric characteristics, the temperature stratification pattern in the mixing box is most sensitive to the damper positions and that the measurement bias is linearly proportional to the difference between the return air and outdoor air temperatures. The measurement is also very sensitive to the positions of the sensing probes but is not very sensitive to the value of the total supply airflow rate or the authorities of the dampers.

The following bias estimator is therefore proposed:

$$
\mathrm{B}_{\text {Tmix }}=\left(\mathrm{T}_{\text {out }}-\mathrm{T}_{\text {ret }}\right) * \mathrm{f}(\mathrm{Ud})
$$

where: $\mathrm{f}(\mathrm{Ud})=\frac{\mathrm{B}_{\text {Tmix }}}{\mathrm{T}_{\text {dif }}}=\sum_{\mathrm{i}=1}^{\mathrm{n}+1} p(\mathrm{i}) * \mathrm{Ud}^{\mathrm{n}-\mathrm{i}+1}$

The coefficients $\mathrm{p}(\mathrm{i})$ are obtained by fitting the simulation results to an $n t h$ order polynomial. The estimated bias is used to correct the output from the sensors. Thus:

$$
\hat{T}_{\text {true }}=T_{\text {meas }}-\hat{B}
$$

Experiments have been performed on a laboratory test rig, in which commercial single-point and twopoint averaging sensors are installed to measure the mixed air temperature. The measurements from both sensors were collected at various positions of the mixing box dampers. Figure 9 compares the raw and corrected values when the return dampers are 50\% open and the supply air flow rate is increased from zero to its design value.

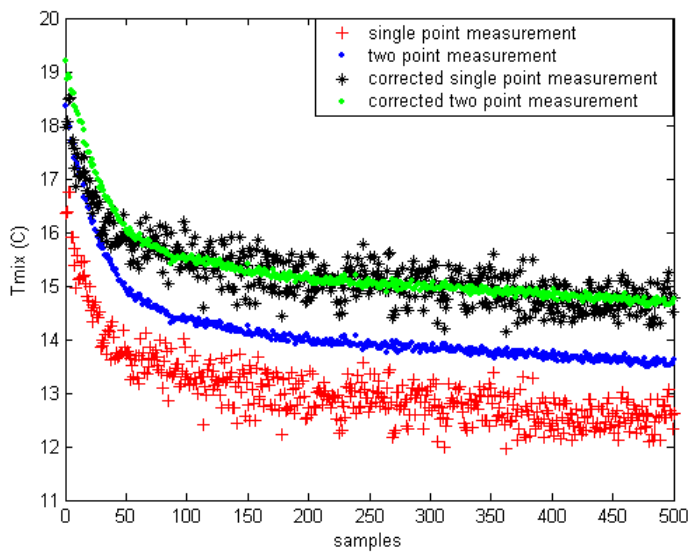

Fig. 9 Direct and corrected measurements with return dampers $50 \%$ open

The experiment results show that the raw measurements from the two sensors are in good agreement initially, when there is no flow through the mixing box. There are, however, large biases associated with the uncorrected outputs of both sensors at the design flow rate (if it is assumed that the corrected values from the two-point sensor are close to the true values of the average mixed-air temperature). It can also be seen that the corrected values of the measurements from the sensors are in good agreement.

\section{CONCLUSIONS AND FUTURE WORK}

The aim of the estimation schemes proposed in this paper to reduce the measurement uncertainties in airconditioning systems without increasing the instrumentation costs.

The results presented in this paper have shown that: 
1.) Airflow rates can be estimated from actuator control signal with an accuracy of better than $10 \%$ of full-scale, if onsite calibration is possible;

2.) The CFD simulation results can produce a satisfactory estimate of the measurement bias;

3.) A more accurate measurement of the average value of the air temperature downstream of the mixing box can be obtained if the estimated bias is used to correct the output of the commercial sensor.

There are, however, some disadvantages:

1.) As is the case with many commercial differential flow sensors, on-site calibration is necessary to determine the parameters in estimation equation (1).

2.) The estimates of the inlet air flow rate will be biased if the assumption that the pressures $P_{\text {in }}$ and $P_{\text {ext }}$ is not valid (for example, when there are wind effects).

3.) Although, the same simulation model can be used for a range of mixing boxes, which have similar constructional characteristics, CFD modelling of the mixing box is necessary to estimate the measurement biases caused by the stratification of the air.

Ways in which the estimated flows and temperatures can be used in simultaneous gross error elimination and data reconciliation schemes are now under investigation.

\section{REFERENCES}

ANNEX 34 (2001). Demonstrating automated fault detection and diagnosis in real buildings. International Energy Agency IEA Energy Conservation in Buildings and Community Systems, Technical Research Centre of Finland, ESPOO 2001;

Avery, G. (2002). Do Averaging Sensors Average? ASHRAE Journal, 44(12), pp42-43;

Carling, P. and P. Isaksson, (1999). Temperature measurement accuracy in an air-handling unit mixing box, $3^{\text {rd }}$ International Symposium on HVAC, ISHAC'99, Shenzhen, China;

Carling, P. and Y. Zou (2001). A comparison of CFD-simulations and measurements of the temperature stratification in a mixing box of an air-conditioning unit. International Journal of Energy Research, 25, pp.643-651;

Crowe, C.M. (1996). Data reconciliation-Progress and challenges. Journal of Process Control, 6, pp.89-98;

Drees, K.H., J.D. Wenger and G. Janu (1992). Ventilation airflow measurement for ASHRAE standard 62-1989. ASHRAE Journal, 34(10), pp.40-45;
Felker, L. (2002). Minimum outside air damper control. ASHRAE Journal, 44(4), pp.30-36;

Kao, J.Y. and E.T. Pierce (1983). Sensor errors and their effects on building energy consumption, ASHRAE Journal, 25(12), pp.42-45;

Kelso, R.M.K., P.H. Marshall and A. J. Baker (2000). A CFD Study of Airflow in a Mixing Box, CIBBE/ASHRAE conference in Dublin, Ireland;

Lee, P.S. and A.L. Dexter (2002). A fuzzy approach to fault diagnosis in the presence of sensor bias. Proc. IEEE Int. Conference FUZZ02, Melbourne, Australia, pp. 1585-1588.

Lee, P.S. and A.L. Dexter (2005). A fuzzy sensor for measuring the mixed air-temperature in airhandling units, Measurement, 37(1), pp.8393;

Legg, R.C. (1986). Characteristic of single and multiblade dampers for ducted air systems, Building Services Engineering Research \& Technology, 7(4), pp.129-145;

Mainkar, M., F. Finaish, H.J. Sauer and R.V. Becelaere (2004). Thermal mixing of outdoor and return airflows in typical air-handling units, ASHRAE Transaction, 110(1);

Musick, S. and K. Kastella (2002). Bias Estimation in an association-free nonlinear filter, Digital Signal Processing, 12, pp.484-493,

Özyurt, D.B. and R.W. Pike (2004). Theory and practice of simultaneous data reconciliation and gross error detection for chemical processes. Computers \& Chemical Engineering, 28(3), pp.381-402;

Price, B. A. and T. F. Smith (1998). Description of the Iowa Energy Centre Energy Resources Station: Facility Update.

Robison, K.D. (1999). Mixing effectiveness of AHU combination mixing/filter box with and without filters. Transactions of ASHRAE, 105(1), pp.88-95;

Singh, S.R., N.K. Mittal and P.K. Sen (2001). A novel data reconciliation and gross error detection tool for the mineral processing industry. Minerals Engineering, 14, pp.809814;

Solberg, D.W., D.S. Dougan and L.A. Damiano (1990). Measurement for the control of fresh air intake, ASHRAE Journal, 30(1), pp.46-51;

Tan, H. and A.L. Dexter, (2004). Estimating airflow rates in air-handling units from actuator control signals, Internal Report, Department of Engineering Science, University of Oxford;

Wang, F., X. Jia, S. Zheng and J. Yue, (2004). An improved MT-NT method for gross error detection and data reconciliation, Computers \& Chemical Engineering, 28(11), pp. 21892192;

Wang, S. and J.B. Wang (1999). Law based sensor fault diagnosis and validation for building airconditioning systems, HVAC\&R Research, 5(4), pp. 353-380. 